\title{
Not as similar as thought: sexual dichromatism in Chimango Caracaras is expressed in the exposed skin but not in the plumage
}

José Herná n Sarasola · Juan José Negro ·

Marc Joseph Bechard · Agustín Lanusse

\begin{abstract}
Many of the mechanisms involved in visual signalling in birds are based on pigment-based plumage ornamentation and colouration rather than the expression of other, non-plumage-based displays. We have analysed the colouration of the tarsi and ceres of free-ranging Chimango Caracaras Milvago chimango, a controversial morphological trait for this species, and examined the proximal causes related to the expression of colour in these featherless body parts. The tarsi-ceres of 81 Chimango Caracaras captured in central Argentina between 2005 and 2008 were either yellow-yellow or bluish-pink coloured. Differences in colour were not linked with plasma carotenoid levels and did not vary seasonally. Rather, expression of the two colours was affected by the gender and age of individuals. Yellow-coloured tarsi and ceres were recorded only in adult males, while the remaining age and gender groups showed pinkish- and bluish-coloured bare parts, which is the suspected neutral developmental stage under low hormonal levels. These results support sexual rather than natural selection forces acting on the expression
\end{abstract}

Communicated by Jon Fjeldså.

J. H. Sarasola • M. J. Bechard • A. Lanusse

Centro para el Estudio y Conservación de las Aves Rapaces en Argentina (CECARA), FCEyN—UNLPam, Avda. Uruguay 151, 6300 Santa Rosa, La Pampa, Argentina

J. H. Sarasola ( \&) • J. J. Negro

Departamento de Ecología Evolutiva,

Estación Biológica de Doñana CSIC,

Avda. Américo Vespucio s/n, 41092 Sevilla, Spain

e-mail: sarasola@ebd.csic.es

M. J. Bechard

Raptor Research Center, Department of Biological Sciences, Boise State University, Boise, ID 83725, USA of yellow colouration in the bare parts of adult males. However, an exaggeration of yellowish colour during mating periods in accordance with an increase of circulating carotenoid levels may be expected due to the sexually-related nature of this trait. This documented partitioning of colour variation among sexes and ages that is unrelated to melanin-dependent plumages is unusual and contrary to the most widely observed types of sexual dichromatism in birds.

Keywords Sexual dichromatism • Chimango Caracara • Milvago chimango $\bullet$ Skin colour $•$ Sexual selection $•$ Visual signalling

Zusammenfassung Viele der Mechanismen für den Austausch visueller Signale bei Vögeln beruhen auf pigmentbasiertem Gefiederschmuck und -farbe statt auf der Zurschaustellung anderer, von den Federn unabhängiger Signale. In unserer Untersuchung analysierten wir die Farbgebung der Tarsi frei lebender Chimangokarakaras (Milvago chimango), einer für diese Art kontrovers beschriebenen morphologischen Eigenheit, und prüften die proximalen Ursachen für die Farbgebung dieser federlosen Körperteile. Die Tarsi-Ceres der 81 zwischen 2005 und 2008 in Argentinien gefangenen Chimangokarakaras waren entweder gelblich oder pink-blau. Die Farbunterschiede zeigten weder einen Zusammenhang mit den CarotinoidPegeln im Plasma, noch jahreszeitlich bedingte Unterschiede. Stattdessen gab es einen Zusammenhang mit dem Geschlecht und dem Alter der Tiere. Gelbe Tarsi und Ceres traten nur bei erwachsenen Männchen auf, während diese Körperteile bei den übrigen Geschlechts- und Altersgruppen pink und bläulich waren, dem vermuteten neutralen Entwicklungsstadium bei niedrigen Hormonpegeln. Diese Ergebnisse sprechen eher für einen Geschlechtsunterschied 
als für einen Selektionsdruck auf die Ausbildung gelber Färbung der federlosen Körperteile ausgewachsener Männchen. Es wäre dann allerdings zu erwarten, dass die gelbe Färbung während der Balzzeit besonders stark ausgeprägt sein würde, zusammen mit einem Anstieg des Karotinoid-Pegels. Im Gegensatz zu der in der Regel beobachteten geschlechtsbedingten Färbung bei Vögeln ist dieses Ergebnis insofern ungewöhnlich, als es eine unterschiedliche Farbgebung bei Geschlechts- und Altersgruppen aufzeigt, die nicht mit der Melanin-abhängigen Gefiederfärbung zusammenhängt.

\section{Introduction}

Visual signals play an important role in intra- and interspecific communication in animals (Maynard-Smith and Harper 2004). The recognition and understanding of such signals and the analysis of the factors determining the variability of their expressions have formed the basis of much of current behavioural and evolutionary ecological theory. The expression of animal visual displays is also a useful tool for researchers aiming to differentiate individuals having some particular individual phenotypic or genotypic characteristic, such as gender, age, individual quality or social status. However, humans find some types of signals difficult to identify and interpret, perhaps due to our sensory biases toward more conspicuous and easily observed visual displays (Coleman 2009). This is particularly true in the study of birds, as most of the research on visual signalling in this group is based on plumage ornamentation and colouration rather than the expression of other, non-plumage-based displays (but see Negro et al. 2006; Parejo et al. 2010).

The Chimango Caracara (Milvago chimango) is one of the most common raptors in South America, with a range that includes Argentina, Chile, Uruguay, Paraguay, southern Bolivia and southeastern Brazil (Del Hoyo et al. 1994; Fergusson-Lees and Christie 2001). The Chimango is typically described as a sexually monomorphic species. Dorsally, its feathers are cinnamon-brown and ventrally, its neck, chest, abdomen and belly feathers are light brown. There is only a slight difference in size between the two sexes (Fergusson-Lees and Christie 2001). Although there is a general agreement on the species' plumage pattern and colour, its tarsus and cere colouration has been variably described in the ornithological literature, field guides and handbooks. While some authors have not specifically described or mentioned the colouration of these bare parts at all (Olrog 1968; Sick 1993; Rodríguez-Mata et al. 2006), others have briefly stated that individuals exhibit a pinkish cere and light-grey or bluish tarsus (Brown and Amadon 1968; Blake 1977; Del Hoyo et al. 1994). Narosky and Yzurieta (2003) described the species as having a bluish tarsus but did not mention cere colouration. Others, however, have stated that Chimango Caracaras exhibit a combination of yellowish ceres and light-grey or bluish tarsi (De la Peña and Rumboll 1998; Fergusson-Lees and Christie 2001). Only Muñoz-Pedreros et al. (2004) have suggested that both yellow and grey colour patterns can occur in the tarsi of Chimango Caracaras, further stating that tarsus colouration is a sexual trait in which a yellow colouration differentiates females from the greyish-coloured males. Although these authors do not provide empirical support for their hypothesis, the supposition that the brightest colouration occurs in females instead of males is striking and contrary to theoretical and empirical observations that generally support the view that sexual dichromatism evolves due to sexual selection on, and deviation in, exaggerated male traits (Anderson 1994).

In sexually dichromatic bird species, most of the brightyellow, red and orange colourations are due to carotenoid pigments (Hill 2002; McGraw 2006; but see Toral et al. 2008). In birds, and particularly in some birds of prey, carotenoids may also be responsible for the colouration of featherless body parts (Bortolotti et al. 1996, 2003; Negro et al. 1998). Carotenoid-based colouration operates as a dynamic condition-dependent signal (McGraw and Ardia 2003) since pigments stored in external tissues (either feathers or bare parts) can be reallocated to other tissues in accordance with physiological needs which would, in turn, vary over time (Alonso-Alvarez et al. 2004; Gautier et al. 2008). These features provide carotenoid-based signals with a great potential for sexual selection (Lozano 1994), which undoubtedly is one of the driving forces behind so many studies on caroteonid-based signals and sexual dichromatism in birds. There are, however, numerous secondary sexual characteristics in birds that are developed under hormonal rather than pigment-intake control (Owens and Short 1995).

In the study reported here, we analyzed the colour patterns of the bare parts of Chimango Caracaras with the aim of analysing the proximal causes related to the expression of tarsus and cere colouration in this species by examining the incidence of individually based variables. We were also interested in testing whether the observed tarsus and cere colours change seasonally and whether differences in the colour of such featherless body parts parallel differences in plasma carotenoid profiles, as would be expected in a carotenoid-based trait (Tella et al. 2004).

\section{Methods}

\section{Data collection}

We captured Chimango Caracaras from December 2005 to October 2008 using a walk-in trap (Bloom et al. 2007) 
baited with meat. Individual birds were trapped in periurban and rural areas close to Santa Rosa town in La Pampa province, central Argentina. The captured birds were measured and banded and, prior to release, the age of the birds (juvenile or adult) was determined based on plumage characteristics (Fergusson-Lees and Christie 2001) or external features (brood patch, cloacal protuberance, moult). A third category of sub-adult individuals included birds with morphological features that did not match either adult or juvenile age stages.

The reflectance spectra of the tarsus and cere colouration for the first 16 Chimangos captured were measured in the range of 360-749 nm using a Minolta CM-2600d portable spectrophotometer (Minolta, Osaka, Japan) with UV (xenon flashlight source) and visible light (standard illuminant D65). For the remaining individuals, and based on the colour pattern observed in the first sub-set of birds captured, colouration of the tarsus and cere was classified as either yellow coloured or pale (i.e., light-bluish tarsus and light-pink cere) (see Figs. 1, 2a).

Approximately $1 \mathrm{ml}$ of blood was taken from each bird from the brachial vein using a heparinized syringe. The blood was placed in tubes and kept in a cooler until centrifugation (3,000 rpm $910 \mathrm{~min})$, which occurred within
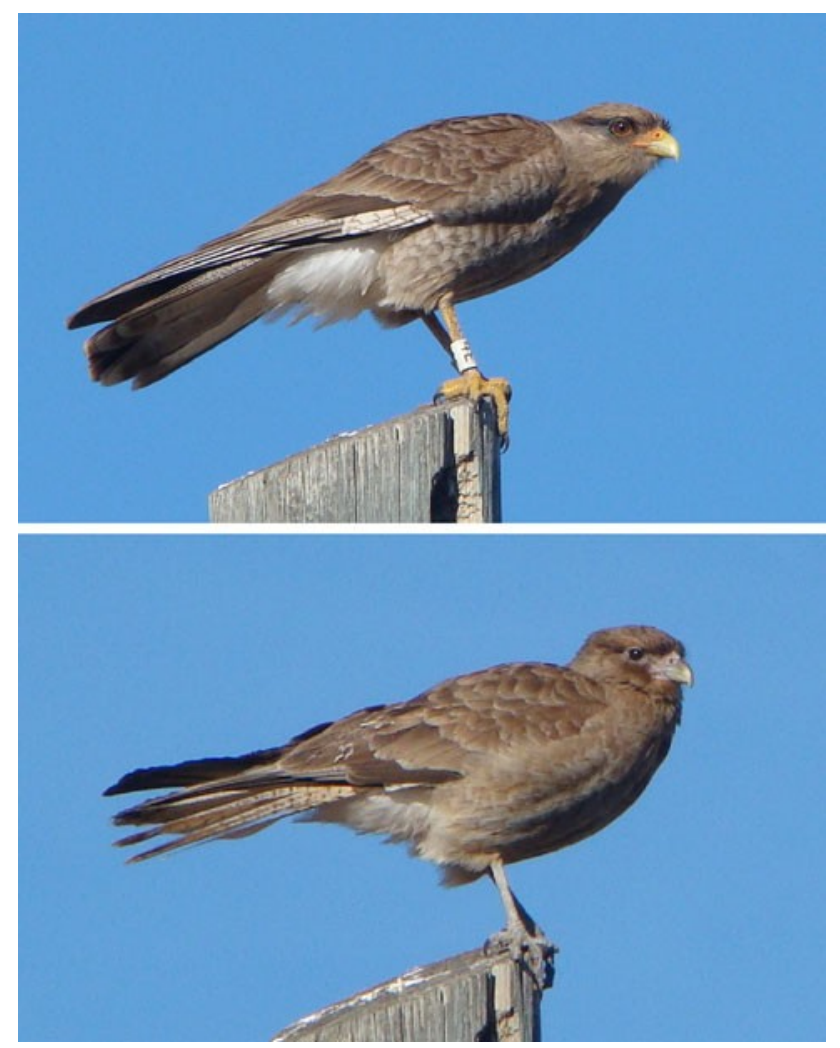

Fig. 1 Wild Chimango Caracara (Milvago chimango) showing lightbrown plumage and the two distinct colour patterns of colouration of the ceres and tarsi recorded for birds captured during the study (colour figure online)
$2 \mathrm{~h}$ after sample collection, and the plasma was then stored at $-20^{\circ} \mathrm{C}$ until analysis. The methodology of Bortolotti et al. (1996) was used to quantify plasma carotenoids. A 0.1 -ml aliquot of plasma was diluted in acetone (1:10) and mixed well; the flocculated protein was precipitated by centrifuging the sample at $10,000 \mathrm{rpm}$ for $10 \mathrm{~min}$. The supernatant was examined in a Spectrum 1102 spectrophotometer (Shanghai Spectrum Instruments, Shanghai, China), and the optical density of the carotenoid peak at $450 \mathrm{~mm}$ was determined. The cellular fraction of the blood sample was used to sex all individuals. For this analysis, we used primers $2550 \mathrm{~F}$ and $2718 \mathrm{R}$ to amplify the $\mathrm{W}$ chromosome gene following the procedure of Ellegren (1996).

\section{Statistical analysis}

We used Generalized Linear Models (GLM; McCullagh and Nelder 1989) to examine variation in tarsus and cere colour of Chimango Caracaras related to sex, age, season and carotenoid concentration in the plasma of birds. For this procedure, we used sex and age as covariables, with two- and three-level factors divided in "male" or "female" and in "juvenile", "sub-adult" or "adult", respectively. The ecology of the Chimango Caracara is poorly known, and there is no information available on the beginning and extent of the breeding season that would allow, for example, the establishment of a relationship between mating season and tarsus and cere colouration. Due to absence of data, we considered this variable on a meteorological basis and entered it as a categorical factor with four levels: spring, summer, winter and autumn. Plasma caroteonid concentration was also entered as a covariable in the model. Models were fitted by using a forward stepwise procedure in which significant effects $(P \backslash 0.05)$ were retained. The model was built using logit link function and binomial errors. Values reported are the mean \pm 1 standard deviation (SD).

\section{Results}

A total of 81 Chimango Caracaras were captured and sampled during the study period. The bare body parts examined were either yellow- (31\% of individuals) or bluish-pink-coloured (69\%). In each individual bird caught, the colour pattern for both tarsi and ceres was always linked, with all birds having either yellow- or blue-coloured tarsi also having either yellow- and pink-coloured ceres, respectively (Fig. 2a). These two colour patterns of tarsi and ceres were represented in the sub-sample of the first 16 individuals caught and for which reflectance spectra of these bare parts was measured. The reflectance spectra curves for the skin of these birds showed two distinct shapes 
(a)
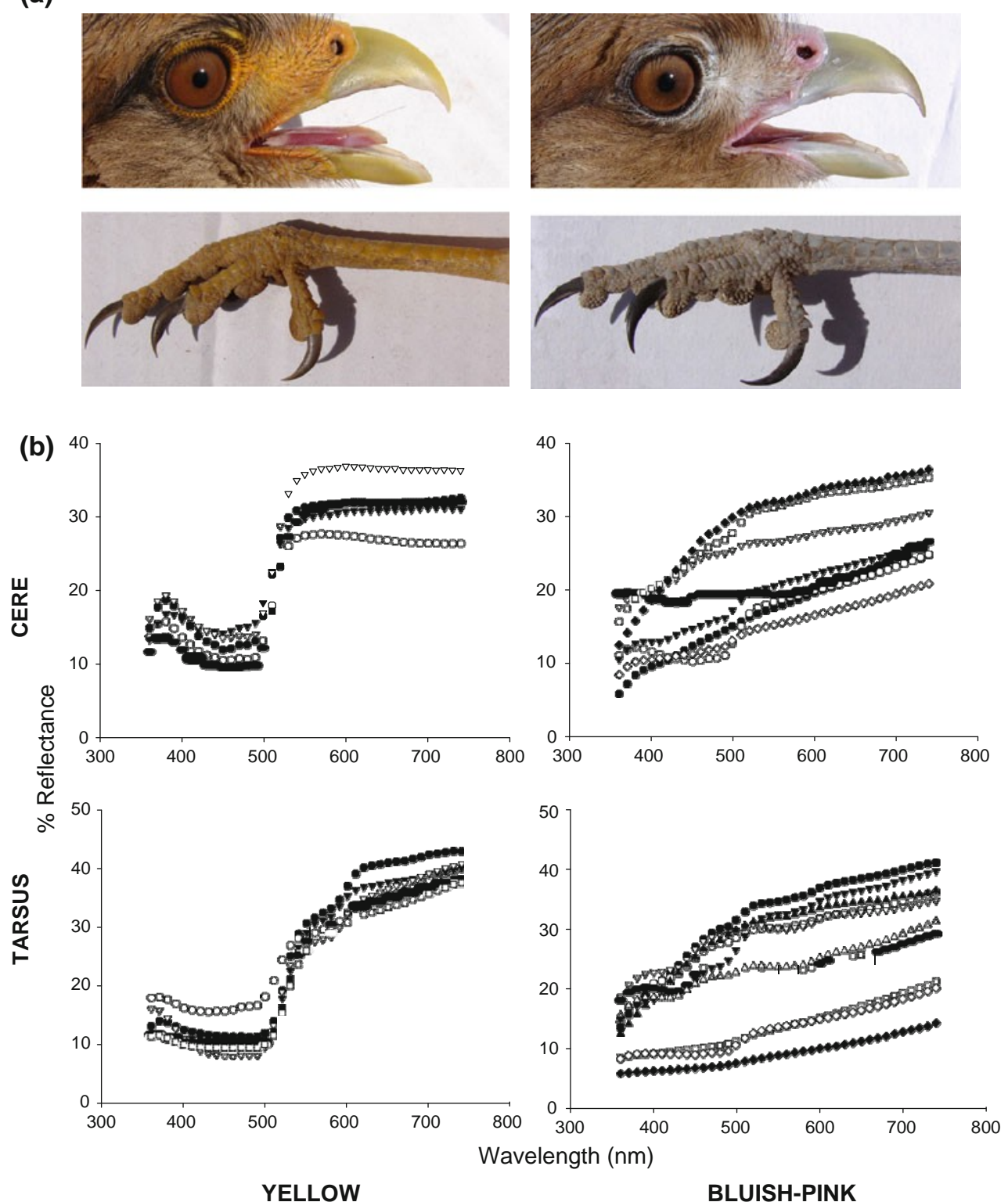

BLUISH-PINK

Fig. 2 Details on tarsus and cere colouration in Chimango Caracaras (a) and corresponding general spectral profile (\% of reflectance as function of wavelength) for yellow and bluish-pink-coloured bare parts $(\mathrm{n}=16)(\mathrm{b})$ (colour figure online)

(Fig. 2b), with the reflectance of yellow tarsi and ceres showing a sigmoid, S-shaped curve with a long wavelength plateau typical for this colour, while bluish-pink-coloured tarsi and ceres showed a linear relationship between percentage of reflectance and wavelength (Fig. 2b).

At 570-nm wavelength, which is the maximum value of reflectance for yellow in the visible spectra, the intraindividual differences were insignificant when compared to mean reflectance values for ceres $(29.9 \% \pm 1.7)$ and tarsi $(29.0 \% \pm 7.1)$ of yellow-coloured birds $(\mathrm{t}=-0.31$, $\mathrm{df}=10, \mathrm{P}=0.75)$. Non-significant differences were also found when we compared cere $(28.4 \% \pm 5.4)$ and tarsus $(30.6 \% \pm 9.1)$ reflectance at the maximum of $740 \mathrm{~nm}$ wavelength for bluish-pink-coloured individuals $(\mathrm{t}=$ -0.61 , $\mathrm{df}=16, \mathrm{P}=0.55$ ). Considering the point for maximum values at each of these reflectance curves (570 and $740 \mathrm{~nm}$ for yellow and bluish-pink colouration, respectively), yellow tarsi were less variable in terms of their coefficient of variation $(\mathrm{CV}=5.7)$ than bluecoloured tarsi $(\mathrm{CV}=29.8)$, yellow ceres $(\mathrm{CV}=24.5)$, and pink-coloured ceres $(\mathrm{CV}=19.2)$ (Fig. 2b).

Because of the complete agreement between tarsus and cere colouration for each individual, we restricted further analyses to only tarsus colouration. Based on the whole sample of birds caught during the 3-year study period, the colour of tarsi was not affected by season $\left(F_{3,77}=1.63\right.$, 
$\mathrm{P}=0.19)$ nor by plasma carotenoid concentration $\left(F_{1,79}=0.08, P=0.77\right)$. However, the colour of the bare parts varied with the sex $\left(\mathrm{F}_{1,79}=209.3, \mathrm{P} \backslash 0.0001\right)$ and age $\left(F_{2,78}=0.08, P \backslash 0.0001\right)$ of birds. Molecular sexing revealed that all birds having yellow bare parts were males, whereas those with bluish-pink-coloured ceres and tarsi were either females or males. In addition, all birds with yellow tarsi and ceres were adult males, while those exhibiting bluish-pink-coloured bare parts were either adult females or juvenile and sub-adult of both sexes (Fig. 3).

\section{Discussion}

The Chimango Caracaras examined in our study exhibited two distinct patterns of tarsus and cere colouration, with the bare parts all being yellow or all being bluish-pink-coloured. Co-occurrence of these two phenotypes within the same population ruled out any geographic variation that would explain the contradictory appearance of this morphological trait in the ornithological literature. Reflectance curves for yellowish ceres and tarsi showed a sigmoid shape similar to that recorded for yellow bare parts in the face of another closely related Neotropical raptor, the Southern Caracara (Polyborus plancus) (Negro et al. 2006). The yellowish cere was also one of the most variable traits of the four body part colour combinations examined. This variability may be due to a mix of carotenoid- and haemoglobin-based colouration acting in this bare part similar to that observed in the flushing faces of Southern Caracaras (Negro et al. 2006), which are also in the family Falconidae.

The tarsus and cere colouration exhibited by Chimango Caracaras was linked to the gender and age of the birds.

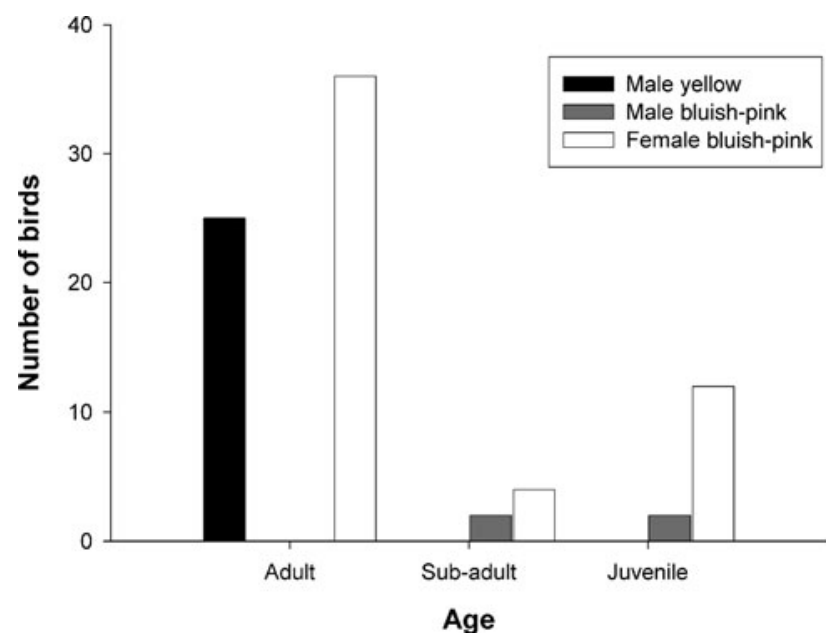

Fig. 3 Age and gender variation in tarsus and cere colouration in Chimango Caracaras. Bars denote birds for each gender and age group with yellow or bluish-pink-coloured bare skin parts (colour figure online)
However, although determined by gender, such an effect is opposite to that previously suggested by Muñoz-Pedreros et al. (2004). Our results show that the more conspicuous yellow colouration was exhibited only by adult males, while the remaining combinations of sex and age groups showed pale bare parts. In addition, the colour of the tarsi and ceres was fixed by these two factors, and neither circulating carotenoid levels nor season had any effect. This partitioning of colour variation among sexes and ages has been recognized in raptors and many other bird taxa, but it has been mainly related to melanin-dependent plumages. In these species, females and immature birds typically share cryptic colourations, whereas adult males are the showier sex and age class [see, for example, patterns of dichromatism in kestrel species, including the Lesser Kestrel (Falco naumanni), Eurasian Kestrel (Falco tinnunculus), or Red-footed Falcon (Falco vespertinus), all of which are in the family Falconidae].

Plasma carotenoid levels were not directly linked to any variation in the colour of the bare parts in Chimango Caracaras, suggesting that the expression of the yellowish colouration in tarsi and ceres is a secondary sexual trait under hormonal control-either testosterone or oestrogen-that may seasonally affect the bioavailability of carotenoids in the gut once food is ingested (Blas et al. 2006). It is uncertain, however, just when male chimangos acquire the yellow colouration in their featherless body parts. Field records on the sexual behaviour of Chimango Caracaras confirm that birds with yellow tarsi adopt a male posture during copulation (A. Lanusse and J.H. Sarasola, personal observation), indicating that yellow-coloured birds are males and that they are sexually mature. Bluish is the typical tarsi colour pattern for male and female nestlings of Chimango Caracaras (Solaro, personal communication). Such gender similarities also seem to be retained during the first life history stages since no differences in the colouration of bare parts was observed for individuals aged as juvenile or sub-adult in both genders (Fig. 2). Accordingly, the non yellow colouration may be the neutral development state of Chimango Caracaras, being produced in both sexes under low hormonal levels.

Although coarse differentiation in tarsus and cere colouration was not linked with circulating plasma carotenoids and did not vary seasonally, a carotenoid-based effect in the yellow hue and brightness of males, and possibly seasonal fluctuations in such values, should not be discarded. Minor sex differences in plasma are also present in other bird species with carotenoid-based, sexually selected traits (Toomey and McGraw 2009), and such similarities have been explained by different allocation strategies of pigments in different tissues related to sex-specific lifehistory and seasonal requirements of carotenoids (McGraw 
and Toomey 2010). If the expression of a yellow colouration in males is exaggerated during the breeding and prebreeding seasons (i.e. increase of brightness and/or hue), then a sexual rather than natural selection force would be operating. Nevertheless, our coarse level colour classification only allowed for discrimination on the two more relevant and visually detectable tarsus and cere colouration patterns (i.e., yellow and bluish-pink-coloured). Such a level of colour categorization precludes a finely tuned analysis of seasonal variation of yellow brightness and hue in the male tarsus and cere that would confirm this is as a sexually selected trait.

Tarsus and cere colouration is a morphological trait that has been overlooked to date as a signal for gender discrimination in Chimango Caracaras. To a lesser extent, this morphological feature is also a reliable method for determining age in some age stages: application of this methodology in behavioural studies would enable a rapid and accurate assignment of the sex and age of wild birds. This sexually dimorphic characteristic also opens the door to future research focused on the potential inter- and intraindividual visual signalling of tarsus and cere colouration in the species.

Acknowledgments We are grateful to Miguel Santillán, Maximiliano Galmes, Claudina Solaro, María Soledad Liébana, Sonia Cabezas, Marcos Reyes, Laura Beinticinco, Hebe Álvarez, Andrea Costan, Juan Ignacio Zanón-Martínez, Elena Macías, and Camila and Lucía Sarasola for help in trapping Chimango Caracaras. This study received financial support from the Universidad Nacional de La Pampa (Argentina), Idea Wild (USA) and the Raptor Research Center, Boise State University. JHS was founded by the National Research Council of Argentina (CONICET) and the Spanish Ministry of Education and Science through the postdoctoral program "Juan de la Cierva”. This study was carried out with permission from the Dirección de Recursos Naturales de la Provincia de La Pampa.

\section{References}

Alonso-Alvarez C, Bertrand S, Devevey G, Prost J, Faivre B, Sorci G (2004) Are carotenoids limiting ressources? An experimental test of dose-dependent effect of carotenoids and immune activation on sexual signals and antioxidant activity. Am Nat 164:651-659

Anderson M (1994) Sexual selection. Princeton University Press, Princeton

Blake ER (1977) Manual of neotropical birds, vol 1. Spheniscidae (Penguins) to Laridae (Gulls and Allies). University of Chicago Press, Chicago

Blas J, Pérez-Rodriguez L, Bortolotti GR, Viñuela J, Marchant TA (2006) Testosterone increases bioavailability of carotenoids: insights into the honesty of sexual signaling. Proc Natl Acad Sci USA 103:18633-18637

Bloom PH, Clark WS, Kidd JW (2007) Capture techniques. In: Bird $\mathrm{D}$, Bildstein KL (eds) Raptor research and management techniques. Hancock House, Blaine, pp 193-220

Bortolotti GR, Negro JJ, Tella JL, Marchant TA, Bird DM (1996) Sexual dichromatism in birds independient of diet, parasites and androgens. Proc R Soc Lond B 263:1171-1176
Bortolotti GR, Fernie KJ, Smits JE (2003) Carotenoid concentration and coloration of American kestrels (Falco sparverius) disrupted by experimental exposure to PBBs. Funct Ecol 17:651-657

Brown L, Amadon D (1968) Hawks, eagles and falcons of the word. McGraw-Hill Book, New York

Coleman SW (2009) Taxonomic and sensory biases in the matechoice literature: there are far too few studies of chemical and multimodal communication. Acta Ethol 12:45-48

De la Peña MR, Rumboll M (1998) Birds of southern South America and Antartica. Harper Collins Publishers, London

Del Hoyo J, Elliot A, Sargatal J (1994) Handbook of the birds of the world, vol 2. New worlds vultures to Guineafowl. Lynx editions, Barcelona

Ellegren H (1996) First gene on the avian W chromosome (CHD) provides a tag for universal sexing of non-ratite birds. Proc $\mathrm{R}$ Soc Lond B 263:1635-1641

Fergusson-Lees J, Christie DA (2001) Raptors of the world. Helm Identification Guides, London

Gautier P, Barroca M, Bertrand S, Eraud C, Gaillard M, Hamman M, Motreuil S, Sorci G, Faivre B (2008) The presence of females modulates the expression of a carotenoid-based sexual signal. Behav Ecol Sociobiol 62:1159-1166

Hill GE (2002) A red bird in a brown bag: the function and evolution of colourful plumage in the house finch. Oxford University Press, New York

Lozano GA (1994) Carotenoids, parasites, and sexual selection. Oikos 70:309-311

Maynard-Smith J, Harper D (2004) Animal signals. Oxford series in ecology and evolution. Oxford University Press, Oxford

McCullagh P, Nelder JA (1989) Generalized linear models, 2nd edn. Chapman and Hall, London

McGraw KJ (2006) Mechanics of carotenoid-based coloration. In: Hill GE, McGraw K (eds) Bird coloration, vol I. Mechanisms and measurements. Harvard University Press, Cambridge, pp 177-242

McGraw KJ, Ardia DR (2003) Carotenoids, immunocompetence, and the information content of sexual colors: an experimental test. Am Nat 162:704-712

McGraw KJ, Toomey MB (2010) Carotenoid accumulation in the tissues of zebra finches: predictors of integumentary pigmentation and implications for carotenoid allocation strategies. Physiol Biochem Zool 83:97-109

Muñoz-Pedreros A, Rau J, Yáñez J (2004) Aves rapaces de Chile. CEA Ediciones, Centro de Estudios Agrarios y Ambientales, Valdivia

Narosky T, Yzurieta D (2003) Guía para la identificación de las aves de Argentina y Uruguay, 15th edn. Asociación Ornitológica del Plata/BirdLife International y Vázquez Mazzini Editores, Buenos Aires

Negro JJ, Bortolotti GR, Tella JL, Fernie KJ, Bird DM (1998) Regulation of integumentary colour and plasma carotenoids in American kestrels consistent with sexual selection theory. Funct Ecol 12:307-312

Negro JJ, Sarasola JH, Fariñas F, Zorrilla I (2006) Function and occurrence of facial flushing in birds. Comp Biochem Physiol A 143:78-84

Olrog CC (1968) Las aves sudamericanas. Fundación Miguel Lillo, Tucumán, Argentina

Owens IPF, Short RV (1995) Hormonal basis of sexual dimorphism in birds: implications for a new theories of sexual selection. Trend Ecol Evol 10:44-47

Parejo D, Aviles JM, Rodriguez J (2010) Visual cues and parental favouritism in a nocturnal bird. Biol Lett 6:171-173

Rodríguez-Mata JR, Erize F, Rumboll M (2006) Birds of South America. Non-passerines: from rheas to woodpeckers. Harper Collins, London 
Sick H (1993) Birds in Brazil: a natural history. Princeton University Press, Princeton

Tella JL, Figuerola J, Negro JJ, Blanco G, Rodriguez-Estrella R, Forero MG, Blázquez MC, Green AJ, Hiraldo F (2004) Ecological, morphological and phylogenetic correlates of interspecific variation in plasma carotenoid concentration in birds. J Evol Biol 17:156-164
Toomey MB, McGraw KJ (2009) Seasonal, sexual, and quality related variation in retinal carotenoid accumulation in the house finch (Carpodacus mexicanus). Funct Ecol 23:321-329

Toral GM, Figuerola J, Negro JJ (2008) Multiple ways to become red: pigment identification in red feathers using spectrometry. Comp Biochem Physiol B 150:147-152 